\title{
Editorial
}

Nephrology

Published online: January 28, 2020

\section{Acute Kidney Injury: To Be or Not to Be: That Is the Question: It's the Company It Keeps}

\author{
Ileana L. Piña \\ Wayne State University, Detroit, MI, USA
}

During the years of 2008-2016, 17,633 continuousflow left ventricular assist devices (LVAD) were implanted in the US [1]. This impressive number over 8 years coincided with the national imperative of reduction in 30-day readmission rates including heart failure [2]. Certainly, patients who are implanted with LVADs are the sickest, whether transplant, destination therapy candidates or bridges to decision with multitude of comorbidities. Comorbidities are known to be highly prevalent in this population and lead to longer length of stay, higher use of resources, and more complications postoperatively [3]. It is reasonable, therefore, to observe a high 30-day readmission rate for LVAD recipients.

Among the most frequent and concerning complications of decompensated and relentless heart failure are the renal abnormalities including acute kidney injury (AKI). This is the topic addressed by Walther et al. [4], in this issue of the American Journal of Nephrology. Using the National Readmissions Database, the authors identified 3 groups of patients with LVAD placement in the context of AKI: no AKI, AKI not requiring dialysis, and AKI with dialysis (AKI-D). They noted that overall the patients with AKI-D had double the odds of being readmitted within 30 days. The cases for inclusion were thoughtfully chosen and elegantly analyzed. The overall readmission rate was $25.4 \%$ which is higher than the current heart failure Centers for Medicare and Medicaid Ser- vices data and certainly higher than most hospital systems would want in their own institutions. The causes of readmissions, independent of AKI, are not surprising and include bleeding and infections.

Are the findings by Walther et al. [4] contradictory to the association of poor outcomes with AKI? This question merits a brief journey into the history of AKI diagnosis. The previous terminology of acute renal failure (ARF) became AKI after much debate and is now accepted with the KDIGO definition from 2012 using primarily changes in serum creatinine and urine volume [5]. The KDIGO Guidelines do admit that the definition includes less severe conditions without actual damage to the kidney but that due to the physiology of renal self-protection and to hemodynamic demands, for example, acute heart failure, the creatinine rises. In addition, the heart may be unable to adapt quickly to therapeutic changes, for example, with the use of RAAS inhibitors which when initiated may actually drop blood pressure but improve survival [6]. Hence, AKI needs to be evaluated within context, by the company it keeps, and efforts to reverse it should be undertaken because it may identify precisely the patients that benefit early from interventions. In the case of Walther et al. [4], the intervention could certainly be the mechanical device. In spite of the 2012 KDIGO definitions, there are 3 other definitions that still exist and are used: AKIN, RIFLE, and Urine Volume [7].

\section{KARGER}

() 2020 S. Karger AG, Basel
Ileana L. Piña

2627 Fairmount Blvd

Cleveland Heights, OH 44106 (USA)

E-Mail ilppina@aol.com 
The AKI definition did not become such in the ICD 9 codes that were identified in the Walther et al. [4] paper given that code 584 and its subheadings include ARF with tubular, cortical necrosis, or medullary necrosis, other pathology and in 584.9 unspecified. The American Academy of Professional Coders recommended using 584.9 for kidney injury [8]. In addition, ICD 9 code 584 describes ARF as pre-renal, renal, and post-renal and thus becomes a sensitivity and lack of specificity issue in the absence of markers of true renal injury.

Much debate has existed on changes in serum creatinine with decompensated heart failure, a population that will often demonstrate changes in serum creatinine during treatment, including necessary diuresis, RAAS inhibitors, and drops in renal perfusion due to low cardiac index [6]. The decompensated heart failure/shock patients make up $61.9 \%$ of the Walther et al. [4], AKI without dialysis population. Perhaps in this group, AKI should be further specified as transient and reversible versus persistent [9]. This separation has been noted in various studies of acute heart failure that have shown that transient worsening of renal function, especially with rises in creatinine, may improve in $1 / 3-2 / 3$ of decompensated $[10,11]$ and post MI patients [12]. Similarly, in a diuretic trial of decompensated $\mathrm{HF}$, rises in serum creatinine using the KDIGO definition of AKI did not translate to worse 60 -day outcomes [13]. The extreme of these populations, that is, the LVAD candidate, is at the far precipice of cardiac decompensation, and although most patients will experience improvement in renal function early post implant in weeks and months due to the improvement in hemodynamics, there are data supporting a slow decline in GFR with time [14].

How to differentiate the transient from the persistent AKI? Further refinement of the AKI without dialysis group in the Walther study could identify the transient versus the persistent, given that those that died during the index hospitalization were excluded and would better explain the similar readmission to the non-AKI group. In fact, the Acute Disease Quality Initiative [15] has suggested that AKI that reverses within $48 \mathrm{~h}$ should define transient AKI, add specificity, and improve prediction of true chronic kidney disease. Others strongly support the need for trustworthy, clinically available, biomarkers to distinguish true kidney injury from hemodynamic changes in GFR as a recent elegant publication from the SPRINT data notes [16]. Both of these suggestions are important given the longterm effects and outcomes of persistent AKI and the growing incidence of AKI diagnoses in North America.

In summary, the Walther et al. [4] study presents some comfort in knowing that only the group with AKI$\mathrm{D}$ had the highest 30 -day readmission rates... an important reflection given that these patients are excluded from the CMS datasets for readmissions and the higher readmission rate post LVAD may escape notice by the hospital quality improvement group. Whether noted or not, this group uses high resources, has longer lengths of stay, and is costly. This important observation could help clinicians allocate resources to the most vulnerable $3.3 \%$ of patients. Nonetheless, isn't it time for the "nephrology world" to take its place among biomarker science rather than relying on definitions of creatinine and urine volume alone?

\section{References}

1 Kirklin JK, Pagani FD, Kormos RL, Stevenson LW, Blume ED, Myers SL, et al. Eighth annual INTERMACS report: special focus on framing the impact of adverse events. J Heart Lung Transplant. 2017 Oct;36(10): 1080-6.

2 Jencks SF, Williams MV, Coleman EA. Rehospitalizations among patients in the Medicare fee-for-service program. N Engl J Med. 2009 Apr;360(14):1418-28.

3 Warraich HJ, Allen LA, Blue LJ, Chaussee EL, Thompson JS, McIlvennan CK, et al. Comorbidities and the decision to undergo or forego destination therapy left ventricular assist device implantation: An analysis from the Trial of a Shared Decision Support Intervention for Patients and their Caregivers Offered Destination Therapy for End-Stage Heart Failure
(DECIDE-LVAD) study. Am Heart J. 2019 Jul;213:91-6.

4 Walther CP; Winkelmayer WC, Deswal A, Niu J, Navaneethan SD. Readmissions after Acute Kidney Injury during Left Ventricular Assist Device Implantation Hospitalization. AmJNephrol.2020,DOI: 10.1159/000505772.

5 Kidney Disease: Improving Global Outcomes (KDIGO) Acute Kidney Injury Work Group. KDIGO Clinical Practice Guideline for Acute Kidney Injury. Kidney inter. Suppl. 2012;2: $1-138$.

6 Polonsky TS, Bakris GL. Heart Failure and Changes in Kidney Function: Focus on Understanding, Not Reacting. Heart Fail Clin. 2019 Oct;15(4):455-61.

7 Okusa MD, Davenport A. Reading between the (guide)lines - the KDIGO practice guide- line on acute kidney injury in the individual patient. Kidney Int. 2014 Jan;85(1):39-48.

8 https://www.aapc.com/blog/31983-renalfailure/.

9 Pinson RD. Acute kidney injury revisited. Terminology is especially important. ACP Hospitalist. Coding Corner; June 2015.

10 Aronson D, Burger AJ. The relationship between transient and persistent worsening renal function and mortality in patients with acute decompensated heart failure. J Card Fail. 2010 Jul;16(7):541-7.

11 Logeart D, Tabet JY, Hittinger L, Thabut G, Jourdain P, Maison P, et al. Transient worsening of renal function during hospitalization for acute heart failure alters outcome. Int J Cardiol. 2008 Jul;127(2):22832. 
12 Goldberg A, Hammerman H, Petcherski S, Zdorovyak A, Yalonetsky S, Kapeliovich M, et al. Inhospital and 1-year mortality of patients who develop worsening renal function following acute ST-elevation myocardial infarction. Am Heart J. 2005 Aug;150(2):330-7.

13 Felker GM, Lee KL, Bull DA, Redfield MM Stevenson LW, Goldsmith SR, et al.; NHLBI Heart Failure Clinical Research Network. Diuretic strategies in patients with acute decom- pensated heart failure. N Engl J Med. 2011 Mar;364(9):797-805.

14 Brisco MA, Kimmel SE, Coca SG, Putt ME, Jessup M, Tang WW, et al. Prevalence and prognostic importance of changes in renal function after mechanical circulatory support. Circ Heart Fail. 2014 Jan;7(1):68-75.

15 Chawla LS, Bellomo R, Bihorac A, Goldstein SL, Siew ED, Bagshaw SM, et al.; Acute Disease Quality Initiative Workgroup 16. Acute kidney disease and renal recovery: consensus report of the Acute Disease Quality Initiative (ADQI) 16 Workgroup. Nat Rev Nephrol. 2017 Apr;13(4):241-57.

16 Malhotra R, Craven T, Ambrosius WT, Killeen AA, Haley WE, Cheung AK, et al.; SPRINT Research Group. Effects of Intensive Blood PressureLowering on KidneyTubuleInjuryin CKD: A Longitudinal Subgroup Analysis in SPRINT Am J Kidney Dis. 2019 Jan;73(1):21-30. 